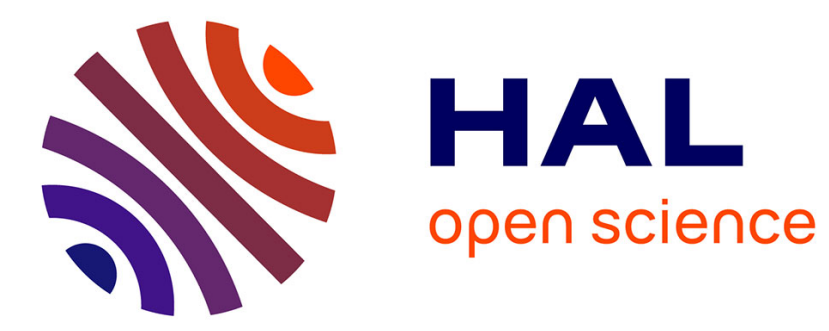

\title{
The WHO mission report struggles to trace the origins of the SARS-CoV-2 epidemic
}

Etienne Decroly, Jean-Michel Claverie, Bruno Canard

\section{To cite this version:}

Etienne Decroly, Jean-Michel Claverie, Bruno Canard. The WHO mission report struggles to trace the origins of the SARS-CoV-2 epidemic. Virologie, In press, pp.1-7. hal-03204818

\section{HAL Id: hal-03204818 \\ https://hal.science/hal-03204818}

Submitted on 21 Apr 2021

HAL is a multi-disciplinary open access archive for the deposit and dissemination of scientific research documents, whether they are published or not. The documents may come from teaching and research institutions in France or abroad, or from public or private research centers.
L'archive ouverte pluridisciplinaire $\mathbf{H A L}$, est destinée au dépôt et à la diffusion de documents scientifiques de niveau recherche, publiés ou non, émanant des établissements d'enseignement et de recherche français ou étrangers, des laboratoires publics ou privés. 


\section{Virologie}

Viewpoint

\section{The WHO mission report struggles to trace the origins of the SARS-CoV-2 epidemic}

Etienne Decroly ${ }^{1 *}$, Jean-Michel Claverie ${ }^{2}$, Bruno Canard ${ }^{1}$.

1 Aix-Marseille Université, CNRS, laboratoire AFMB (UMR7257).

2 PU-PH émérite, Aix-Marseille Université/APHM, Information génomique \& structurale (UMR7256), Institut de Microbiologie de la Méditerranée (FR 3479)

*Corresponding author: etienne.decroly@univ-amu.fr

Today, COVID-19 monopolises the media, paralyses our lives, and obsesses our thoughts. However, many would be astonished to learn that after a year and a half of a pandemic that has taken billions of humans hostage and has already cost the global economy €25 trillion [1], a process to rigorously and thoroughly investigate its possible origins has not been put in place yet. Less energy has been invested in elucidating the causes of this global disaster than in investigating the mysterious disappearance of the Malaysia Airlines Flight 370 on 8 March 2014, killing 239 people [2]. COVID-19 has already caused 3 million deaths worldwide, including 100,000 in France up to April 2021) [3].

Identifying the origins of the SARS-CoV-2 pandemic is a key issue for the prevention and response to future epidemics. After months of negotiations with the Chinese authorities, WHO could send 17 international experts for a joint study with Chinese experts to elucidate the origin of the virus that causes COVID-19. The report of the commission entitled "WHO Joint Global Investigation of the Origins of SARS-CoV-2: Chinese Part" was published in March 2021 [4]. Unfortunately, this study did not allow identifying the cause of the pandemic. However, the report proposes four hypotheses: 1) zoonotic origin followed by transmission via an intermediate host, 2) zoonotic origin with direct transmission from bats, 3) arrival in China via frozen food or the cold chain, and 4) laboratory accident. These working hypotheses are ranked from highly probable to very unlikely by the commission, without any rational explanation for this ranking and despite the fact the laboratory virus escapes have been previously documented $[5,6]$. The WHO Director-General Tedros Adhanom Ghebreyesus welcomed the work of the commission (whose objectivity was called into question in two open letters written by an international group of scientists) $[7,8]$, but did not endorse the report conclusions and declared that all hypotheses remained on the table because the investigation had not been sufficiently thorough. Furthermore, it proposed to send a second expert group with broader powers, including biosafety specialists, with the aim of firmly establishing SARS-CoV-2 origin. Therefore, the investigation process must continue to understand how SARS-CoV-2 was transmitted to humans, probably from the virus reservoir discovered in bats from Southeast Asia. 
Unfortunately, the controversy over the epidemic origin, which initially was a scientific issue, has become part of a political struggle between China and the United States and its closest allies. More than a year after the epidemic start, one might wonder whether it is still possible to solve this question objectively.

Let's go back to the basics, specifically the available robust scientific evidences that might help to inform the debate. First, the sequences of a growing number of SARS-CoV-2-related viruses have been obtained from bat and pangolin samples [9-12]. The analysis of these different viral sequences confirms the high recombination capacity of these coronaviruses, mainly in the genomic region that encodes the "Spike" (S) protein. This protein plays a key role in the recognition of the cell receptor Angiotensin-Converting Enzyme 2 (ACE2) and in the virus entry in the host cells [13-15]. The genomic sequences of these viruses display 89 to $96 \%$ of identity, which corresponds to more than 1200 mutations per genome or decades of biological evolution (in the absence of epidemics or recombination). The closest known ancestor (RaTG13) comes from a sample collected in 2013 in a mine in the Yunnan province, located more than $1500 \mathrm{~km}$ south from Wuhan, where six miners developed an atypical pneumonia form that led to the death of three of them [16]. However, sequence comparison showed that RaTG13 is not the proximal ancestor of SARS-CoV-2, and the direct progenitor is still unknown. A second irrefutable observation is that the COVID-19 epidemic started in Wuhan City in late 2019. The sequences of virus samples collected at the beginning of the epidemic indicate very low genetic variability among these initial isolates [11]. This suggests that the epidemic onset, or at least the spread of a virus with efficient human-to-human transmission, is likely to have occurred between September and October 2019.

The key remaining questions are to understand how the virus that initiated the epidemic spread in Wuhan City, and then to identify the missing links between the viruses circulating in bat populations and the human virus. It is currently believed that crossing the species barrier involves a sequence of events that allow bat viruses to: 1) acquire the ability to use the ACE2 receptors present at the surface of human cells; and 2) increase their inter-human transmissibility by acquiring a proteolytic cleavage site sensitive to furin, an ubiquitously expressed protease [17]. Usually, and fortunately, these two steps constitute a major bottleneck that limits zoonotic transmission and thus the pandemic risks.

From the beginning, the vast majority of the scientific community rapidly proposed zoonotic hypotheses because most viral emergences, including the latest SARS-CoV and MERS-CoV epidemics, are zoonoses for which the intermediate hosts have been quickly identified [15, 16]. Furthermore, serological studies indicate that $0.6 \%$ of the population of Yunnan province has antibodies against SARS-like coronaviruses, compared to $0 \%$ in Hubei province, where Wuhan City is located [20]. This suggests that species transfer is possible, albeit not frequent, in the Yunnan. Fortunately, despite these seroconversions, it seems that the possibility of human-to-human transmission of these viruses is rare, because medical doctors did not observe any viral outbreak. This confirms the existence of a species barrier 
that limits human-to-human transmission. Therefore, the Chinese authorities tried to find evidence of zoonotic transmission (direct or via an intermediate host) in more than 80,000 samples from wild animals, livestock (35 species), and poultry collected in late 2019 and early 2020 [4]. All these samples were negative for viral RNA. Moreover, among the samples collected in Wuhan wet market, only environmental contamination by the human virus was detected. No intermediate animal host could be identified. These experimental observations do not support the main conclusion of the report according to which SARS-CoV-2 was most likely introduced into the human population via an intermediate host. However, lack of proof is not a proof, and it is still possible that SARS-CoV-2 virus passed through an intermediate species susceptible to the virus (e.g. cat, raccoon dog, mink, pangolin, civet cat) without detection of an epizootic outbreak. It should be noted that $15 \%$ of the cats tested in Wuhan after the epidemic had neutralising antibodies against SARS-CoV-2 [21].

The WHO report proposes an alternative hypothesis by stating that when SARS-CoV-2 was circulating widely in the human population in 2020, traces of this virus were found on frozen meat packages. There is little scientific evidence to support this hypothesis, and to our knowledge, there is no documented coronavirus outbreak through frozen meat to date. Yet, this hypothesis could explain how this outbreak started in a megacity of eleven million people where potentially infected animals are rare. It is a politically satisfactory hypothesis for the Chinese authorities, but scientifically weak, without robust evidence. Moreover, it just displaces the problem, without solving the question of the origin.

Finally, the report disqualifies the hypothesis of an accidental origin linked to experimental work on coronaviruses in different laboratories in Wuhan City. It is important to note that the priority of the WHO-China joint study was to investigate a zoonotic origin and not to evaluate all possible sources of the pandemic, and that the mandate negotiated by the WHO does not mention this last hypothesis [4]. This hypothesis is based particularly on the fact that the RaTG13 virus, which is currently the closest known neighbour of SARS-CoV-2, was sampled by a laboratory located close to the area where the first cases of SARS-CoV-2 infection were detected. Research projects carried out at the Wuhan Institute of Virology (and co-funded by the NIH [22]) wanted to understand the mechanism of species barrier crossing used by coronaviruses. These studies involved collecting viruses from bats, their sequencing to estimate their diversity, their culture (if possible) using different cell types to elucidate the mechanism of species barrier crossing, and their propagation in various animal models, including mice that express the human ACE2 receptor [14, 22]. Moreover, this institute has developed strategies to construct chimeric viruses by exchanging receptor recognition domains, as documented by many of their publicly available publications and research projects $[14,23-24]$. The aims of these gain-of-function experiments were to identify the molecular determinants that promote infection of human cells, and to develop vaccine strategies against this potentially pandemic family of viruses. These research programmes are entirely compatible with the hypothesis of a laboratory accident, for example through the contamination (even asymptomatic) of a staff member, or due to a 
negligence in biohazardous waste management. This hypothesis would also explain the emergence of this virus in a city that concentrates the largest centres for coronavirus studies in the world, and where seven separate laboratories (of biosafety level BSL-2 to 4) handle these viruses. It should also be noted that a growing number of laboratories in the world civilian and undoubtedly military- are studying bat viruses, particularly from samples taken in Asia. The hypothesis of a leak from another lab other than the one in Wuhan and its importation, although highly unlikely, cannot be excluded. In the absence of detailed information on the activities of these laboratories, the "accidental leak" is a hypothesis that has not been rigorously evaluated yet.

An important observation, not documented in the WHO report but much discussed in the context of accidental leakage, is the presence of a basic amino acid-rich cleavage site in the $S$ protein at the junction between the S1 and S2 domains $[17,25]$. This proteolytic cleavage site is absent in all currently sequenced SARS-like coronavirus strains. It plays a key role in the human-to-human transmission of the virus and in its ability to infect a broad spectrum of cells. Indeed, the cleavage between the S1/S2 domains, called "priming", induces a conformational change in the $S$ protein that is required for the optimal recognition of the human ACE2 receptor [26]. The origin of this site, which results from the insertion of a 12nucleotide sequence in the coding sequence for the $S$ protein, is discussed in the literature. The supporters of the zoonotic origin propose that the natural insertion of this site is linked to "template switching" mechanisms frequently observed in the case of co-infection by two coronaviruses harbouring sufficiently homologous sequences [27]. On the other hand, the supporters of the laboratory accident argue that many experiments involving the insertion of sites rich in basic amino acids at the S1/S2 junction have already been carried out to potentiate infection by coronaviruses $[28,29]$. They are also surprised by the unexpected presence of two successive arginine codons (CGG), rarely observed in this family of viruses, but classically used in codon re-encoding experiments to promote protein expression in eukaryotic cells. The origin of the furin cleavage site is not clear yet, and more virus sequences are needed to trace SARS-CoV-2 origin, including the SARS-CoV-2 precursor without this cleavage site. Unfortunately, entry to the Yunnan cave is now forbidden, and new sampling is impossible (including by the WHO mission).

Although SARS-CoV-2 origin is still unknown, elucidating the origin of this pandemic remains an essential challenge to adapt measures in order to prevent the emergence of new pandemics. If the zoonotic origin results from the passage through an intermediate host, it will be necessary to take measures to monitor potentially infected animals that might also be candidate vectors of these viruses. This possibility completely shapes our relationship with wild areas and their fauna. For humans, a health risk is the combination of a danger (a microbe that we cannot control) and human exposure (that we can regulate). Ensuring that biodiversity-rich areas are not overly "anthropized" is both necessary for their preservation and to avoid new pandemics. The consumption of bushmeat (and its poaching) must be more closely monitored, and perhaps banned. If the COVID-19 pandemic turns out to be the 
result of a laboratory accident, then the experimental conditions under which potentially pathogenic viruses are collected and studied must be better regulated, particularly "gain-offunction" experiments [30-32]. Although conferring new properties to a virus seems sometimes necessary to understand its pathogenicity, we must ask how the benefit/risk balance of such experiments should be evaluated. Is it reasonable to generate in laboratories viruses that might cause pandemics in humans and do not exist naturally?

This ethical debate on "gain-of-function" experiments has been going on since 2011, when American and Dutch researchers wanted to construct potentially pandemic influenza viruses from a virus that was initially poorly adapted to transmission by aerosol [33, 34]. The main question is whether the expected benefit of these experiments can justify taking the risk, or whether they should be considered too dangerous and therefore banned. This dilemma led the United States to declare a moratorium on this type of experiment from 2014. These trade-offs are complex, and it is necessary to assess the potential risks and benefits of all experiments in order to define limits without amputating virology research. We should also remember that ignorance does not eliminate the danger. Natural biological samples do not necessarily and always end up in high-security laboratories. This might happen only after they are found to contain potentially pandemic viruses. Surprisingly, at a time when voices are being raised about the risk of accidents in the few existing BSL4 laboratories, [35] China has just announced plans to build 23 BSL4 (one per province) and 88 BSL3 laboratories [36]. While waiting for the (unlikely) establishment of an independent international organisation to monitor their activities (which could be modelled on the International Atomic Energy Agency), an emergency solution could be to equip each of these laboratories with a sort of biological "black box" (e.g. an archive of all air filters and electronic laboratory notebooks) that would allow identifying (or exonerating) them as source of accidents or problems.

In conclusion, it is also important to note that the introduction of the mRNA vaccine technology has made it much easier to simultaneously construct a dangerous virus and its vaccine. This technological breakthrough has led to a sudden change of era. The possibility to concomitantly possess these two entities (a virus and its vaccine) introduces a radically new political, strategic and military dimension to which neither virologists nor society should remain indifferent.

\section{References}

[1] Cutler D. M., Summers H. The COVID-19 Pandemic and the \$16 Trillion Virus, JAMA 2020 ; 324 : 1495-1496.

[2] Gregersen E. Malaysia Airlines flight 370 disappearance, Britannica. https://www.britannica.com/event/Malaysia-Airlines-flight-370-disappearance 2021.

[3] Coronavirus Update Worldometer, https://www.worldometers.info/coronavirus/ 2021.

[4] Virus origin / Origins of the SARS-CoV-2 virus. WHO, https://www.who.int/health- 
topics/coronavirus/origins-of-the-virus 2021.

[5] Normile D. SEVERE ACUTE RESPIRATORY SYNDROME: Lab Accidents Prompt Calls for New Containment Program, Science 2004; 304 : 1223-1225.

[6] Heymann D. L., Aylward R. B., Wolff C. Dangerous pathogens in the laboratory: From smallpox to today's SARS setbacks and tomorrow's polio-free world. Lancet, 2004 ; $363: 1566-1568$.

[7] Calls for Further Inquiries Into Coronavirus Origins. The New York Times. https://www.nytimes.com/interactive/2021/04/07/science/virus-inquiries-pandemicorigins.html?referringSource=articleShare 2021.

[8] Some Scientists Question W.H.O. Inquiry Into the Coronavirus Pandemic's Origins. The New York Times. https://www.nytimes.com/2021/03/04/health/covid-virusorigins.html 2021.

[9] Wacharapluesadee S., Tan C. W., Maneeorn P., Duengkae P., Zhu F., et al. Evidence for SARS-CoV-2 related coronaviruses circulating in bats and pangolins in Southeast Asia. Nat. Commun. $2021 ; 12$ : 1-9.

[10] Lam T. T. Y., Jia N., Zhang Y. W., Shum M. H. H., Jiang J. F., et al. Identifying SARS-CoV2-related coronaviruses in Malayan pangolins. Nature. 2020 ; 583 : 282-285.

[11] Zhou P., Yang X. L., Wang X. G., Hu B., Zhang L., et al. A pneumonia outbreak associated with a new coronavirus of probable bat origin. Nature 2020 ; $579: 270-$ 273.

[12] Zhou H., Chen X., Hu T., Li J., Song H., et al. A Novel Bat Coronavirus Closely Related to SARS-CoV-2 Contains Natural Insertions at the S1/S2 Cleavage Site of the Spike Protein. Curr. Biol. $2020 ; 30$ :2196-2203.

[13] Graham R. L., Baric R. S. Recombination, Reservoirs, and the Modular Spike: Mechanisms of Coronavirus Cross-Species Transmission. J. Virol. 2010 ; 84 : 31343146.

[14] Hu H. Zeng L. P., Yang X. L., Ge X. Y., Zhang W., et al. Discovery of a rich gene pool of bat SARS-related coronaviruses provides new insights into the origin of SARS coronavirus. PLoS Pathog. 2017 ; 13 : 1-27.

[15] Sallard E., Halloy J., Casane D., Decroly E., van Helden J. Tracing the origins of SARSCOV-2 in coronavirus phylogenies: a review. Environmental Chemistry Letters. 2021 ; $1: 1-17$.

[16] Rahalkar M. C., Bahulikar R. A. Lethal Pneumonia Cases in Mojiang Miners (2012) and the Mineshaft Could Provide Important Clues to the Origin of SARS-CoV-2. Front. Public Heal. $2020 ; 8$ : 638.

[17] Coutard B., Valle C., de Lamballerie X., Canard B., Seidah N. G., Decroly E. The spike glycoprotein of the new coronavirus 2019-nCoV contains a furin-like cleavage siteabsent in CoV of the same clade. Antiviral Res. $2020 ; 176$.

[18] Song H. D. Tu C. C., Zhang G. W., Wang S. Y., Zheng K., et al. Cross-host evolution of severe acute respiratory syndrome coronavirus in palm civet and human. Proc. Natl. Acad. Sci. U. S. A. $2005 ; 102: 2430-2435$.

[19] Sabir J. S. M. Lam T. T.Y., Ahmed M. M. M., Li L., Shen Y., et al. Co-circulation of three camel coronavirus species and recombination of MERS-CoVs in Saudi Arabia. Science $2016 ; 351: 81-84$.

[20] Wang N. Li S. Y., Yang X. L., Huang H. M., Zhang Y. J., et al. Serological Evidence of Bat SARS-Related Coronavirus Infection in Humans, China. Virologica Sinica $2018 ; 33$ : 104-107. 
[21] Zhang Q. Zhang H., Gao J., Huang K., Yang Y., et al. A serological survey of SARS-CoV-2 in cat in Wuhan. Emerg. Microbes Infect. 2020 ; 9 : 2013-2019.

[22] RePORT, RePORTER. https://reporter.nih.gov/search/66KRDtaoHkmgkLoGUE4Zg/project-details/9819304 2021.

[23] Zeng, L.-P. Gao Y.T., Ge X.Y., Zhang Q., Peng C., et al. Bat Severe Acute Respiratory Syndrome-Like Coronavirus WIV1 Encodes an Extra Accessory Protein, ORFX, Involved in Modulation of the Host Immune Response. J. Virol. 2016 ; 90 : 6573-6582.

[24] Menachery V. D. Youn, B. L., Debbink K., Agnihothram S., Gralinski L. E., et al. A SARSlike cluster of circulating bat coronaviruses shows potential for human emergence. Nat. Med. $2015 ; 21$ : 1508-1513.

[25] Johnson B. A. Xie X., Bailey A. L., Kalveram B., Lokugamage K. G., et al. Loss of furin cleavage site attenuates SARS-CoV-2 pathogenesis. Nature $2021 ; 591$ : 293-299.

[26] Wrobel A. G. Benton D. J., Xu P., Roustan C., Martin S. R., et al. SARS-CoV-2 and bat RaTG13 spike glycoprotein structures inform on virus evolution and furin-cleavage effects. Nat. Struct. Mol. Biol. $2020 ; 27$ : 763-767.

[27] Gallaher W. R. A palindromic RNA sequence as a common breakpoint contributor to copy-choice recombination in SARS-COV-2. Arch. Virol. $2020 ; 165: 2341-2348$.

[28] Cheng J. Zhao Y., Xu G., Zhang K., Jia W., et al. The S2 subunit of QX-type infectious bronchitis coronavirus spike protein is an essential determinant of neurotropism. Viruses $2019 ; 11: 1-14$.

[29] Belouzard S., Chu V. C., Whittaker G. R. Activation of the SARS coronavirus spike protein via sequential proteolytic cleavage at two distinct sites. Proc. Natl. Acad. Sci. U. S. A., 2009 ; 106 : 5871-5876.

[30] Butler D. Engineered bat virus stirs debate over risky research. Nature $2015 ; 11$.

[31] Casadevall A., Shenk T. H5N1 moratorium controversy and debate. mBio 2012 ; 3 : 1 2.

[32] Evans N. G., Lipsitch M., Levinson M. The ethics of biosafety considerations in gainoffunction research resulting in the creation of potential pandemic pathogens. J. Med. Ethics, $2015 ; 41$ : 901-908.

[33] Imai M. Watanabe T., Hatta M., Das S. C., Ozawa M., et al. Experimental adaptation of an influenza $\mathrm{H} 5 \mathrm{HA}$ confers respiratory droplet transmission to a reassortant $\mathrm{H} 5$ HA/H1N1 virus in ferrets. Nature $2012 ; 486: 420-428$.

[34] Russell C. A. Fonville J. M., Brown A.E.X., Burke D. F. Smith D. L., et al. The potential for respiratory droplet-transmissible $A / H 5 N 1$ influenza virus to evolve in a mammalian host. Science $2012 ; 336$ : 1541-1547.

[35] Van Boeckel T. P., Tildesley M. J., Linard C., Halloy J., Keeling M. J., Gilbert M. The Nosoi commute: a spatial perspective on the rise of BSL-4 laboratories in cities. http://arxiv.org/abs/1312.3283 2013.

[36] China goes on biosafety lab building spree. Asia Times https://asiatimes.com/2020/07/china-goes-on-biosafety-lab-building-spree/ 2021. 